\title{
MATEMÁTICA COM ARTE: SUGESTÕES DE ATIVIDADES INTERDISCIPLINARES
}

\author{
Marcelo Bergamini Campos \\ E-mail: marcelo.bergamini@hotmail.com \\ Universidade Estadual de Minas Gerais
}

A obra Matemática com arte: sugestões de atividades interdisciplinares tem caráter essencialmente pragmático. De fato, conforme sugere o título, o objetivo central é apresentar atividades para uso em sala de aula, explorando interfaces entre estas áreas do conhecimento.

O livro é organizado por três pesquisadoras com vasta experiência na formação docente. Julia Schaetzle Wrobel é doutora em Matemática Aplicada pelo Instituto Nacional de Matemática Pura e Aplicada, Clarissa Lopes Trojack é mestra em Educação Matemática pela Pontifícia Universidade Católica do Rio Grande do Sul - PUC-RS e Vanessa Oechsler é doutoranda em Educação Matemática na Universidade Estadual Paulista campus Rio Claro São Paulo - Unesp de Rio Claro, SP.

As organizadoras, juntamente com outros professores de matemática, assumem a autoria dos nove capítulos que compõem a obra e compartilham percepções sobre o processo de ensino e aprendizagem. Eles demonstram a intenção de trazer para a sala de aula atividades que sejam motivadoras e despertem o interesse dos alunos pelo estudo de matemática, além de contribuir para que se constatem as suas aplicações. Nos relatos das experiências desenvolvidas, os autores insistem na perspectiva de romper com a visão que muitos indivíduos têm desta disciplina concebendo-a como uma ciência abstrata e isolada das outras áreas do conhecimento ou mesmo de situações vivenciadas no cotidiano.

No primeiro capítulo, apresentado com o título "Interdisciplinaridade, matemática e arte", as organizadoras discutem os aportes teóricos que sustentam a proposta de conectar estas disciplinas. Partindo de uma discussão sobre a necessidade de enfrentar o que chamam de crise de relevância no ensino da matemática, elas sinalizam suas aplicações no dia-a-dia e nas outras matérias escolares. Apoiadas em Zaleski Filho (2013), apontam aproximações e distanciamentos entre a Matemática e a Arte ao longo da história da humanidade, defendendo um trabalho integrado no contexto escolar. 
Revista Triângulo

ISSN 2175-1609

\section{RESENHA / BOOK REVIEW / RESEÑA}

O segundo capítulo, intitulado "Construção de roupas de boneca e Geometria", apresenta a primeira sugestão de atividade interdisciplinar. A proposta foi desenvolvida com alunos de um curso técnico de Modelagem do Vestuário e envolveu a elaboração e a produção de roupas de papel para uma boneca.

No desenvolvimento do trabalho, os estudantes buscaram inspiração nas criações de um estilista e realizaram pesquisas sobre conceitos e transformações geométricas que posteriormente foram identificadas nas roupas produzidas. Segundo a autora, a experiência contribuiu para despertar o interesse dos alunos pelo aprendizado de geometria e constatar conexões com a modelagem de roupas.

O terceiro capítulo, apresentado com o título "Construção de polígonos e poligramas", relata uma atividade envolvendo construções geométricas, realizada com alunos do sétimo ano do ensino fundamental. Os estudantes construíram polígonos regulares e, a partir destes, elaboraram os poligramas. A autora relata as dificuldades apresentadas pelos alunos no manuseio dos instrumentos de desenho, sinalizando o reduzido espaço que têm encontrado nas aulas de geometria.

O quarto capítulo, intitulado "Escher, isometrias e pavimentação", apresenta o relato de uma atividade idealizada por bolsistas do Programa Institucional de Bolsas de Iniciação à Docência (Pibid) e que foi concretizada em turmas do ensino fundamental de uma escola pública. A proposta foi inspirada no conceito de pavimentação do plano, explorado pelo artista holandês Maurits Cornelis Escher em várias de suas obras. Segundo os autores, o trabalho possibilitou aos estudantes identificar simetrias e explorar isometrias, além de facilitar o reconhecimento da aplicabilidade destes conceitos nas artes e no cotidiano.

A atividade relatada no quinto capítulo é apresentada com o título "Bordando as isometrias" e também foi realizada no contexto do Pibid. A proposta de associar Matemática e Arte tomou como elo a produção e a análise de gráficos de bordados em ponto de cruz e foi desenvolvida com alunos do oitavo ano do ensino fundamental. As autoras afirmam que as pessoas nem sempre observam as regularidades presentes neste tipo de trabalho manual e sinalizam a possibilidade de explorar diversos conceitos geométricos, destacando a percepção das isometrias. 
Revista Triângulo

ISSN 2175-1609

\section{RESENHA / BOOK REVIEW / RESEÑA}

O sexto capítulo é intitulado "Origami e Geometria" e descreve um consistente trabalho que foi desenvolvido com alunos do oitavo período de um curso de licenciatura em Matemática. A oficina explorou a técnica do origami modular para a construção de poliedros e, conforme explicitado pelas autoras, objetivou "apresentar de forma lúdica o origami como recurso para o ensino e aprendizagem de geometria, aliado ao apelo da beleza estética e artística dos modelos construídos" (p. 61).

Inicialmente as autoras sinalizam potencialidades da geometria das dobraduras como estratégia para resolução de problemas, observando a possibilidade de uma discussão da proposta de forma axiomática. Diante desta perspectiva, apresentam dois axiomas e mostram as suas aplicações por meio da determinação da mediatriz de um segmento. Na sequência, apresentam o sistema de diagramação de origami, que é percebido como uma linguagem universal, mencionando os principais traços e setas indicativos de dobras e de movimentos que podem ser feitos com o papel. O leitor também é orientado sobre a construção do módulo Sonobe que é a base para a montagem dos diversos sólidos elaborados na oficina.

A partir dos sólidos construídos, as autoras apontam a possibilidade de explorar as suas nomenclaturas, bem como a percepção de semelhanças ou de diferenças entre eles. Lembram ainda que o uso de papéis em cores e texturas diferentes contribui para impactar no aspecto artístico e visual dos objetos produzidos.

No sétimo capítulo que é intitulado "Mapa semântico, identidade visual, arte e matemática", a autora relata uma experiência desenvolvida com alunas do primeiro ano do ensino médio de um Curso Normal. A situação narrada envolveu a elaboração de mapas semânticos e, a partir destes, a produção de identidades visuais, conceitos que são esclarecidos ao longo do texto.

A autora observa que, no decorrer do trabalho, foi possível explorar conteúdos estatísticos além de contribuir para que os estudantes percebessem o caráter interdisciplinar do conhecimento e constatassem que a matemática se faz presente em diferentes espaços do cotidiano. Ao relatar alguns dos resultados obtidos, ela destaca avanços em aspectos atitudinais e comportamentais, afirmando que foi possível promover um maior autoconhecimento. 
Revista Triângulo

ISSN 2175-1609

\section{RESENHA / BOOK REVIEW / RESEÑA}

“A arte de vestir fractais" é o título do oitavo capítulo. A atividade sugerida explora interfaces entre artes, números complexos e fractais, sendo direcionada a alunos do terceiro ano do ensino médio. A autora discute algumas definições que foram propostas para os fractais e apresenta exemplos de construções, sinalizando, inclusive, o uso do Geogebra. Na sequência, desenvolve uma breve introdução ao estudo dos números complexos e sugere uma conexão das suas representações no plano de Argand-Gauss com os fractais, associada a imagens dos Conjuntos de Mandelbrot. Observa ainda que este trabalho foi facilitado pelo uso de um software e de planilhas eletrônicas.

A sugestão de atividade que encerra a obra é descrita no nono capítulo, intitulado "Performance matemática digital". O trabalho foi realizado com professores e alunos de graduação e envolveu a produção de vídeos abordando temas matemáticos.

Apoiadas em Borba, Scucuglia e Gadanidis (2014), as autoras afirmam que a Performance Matemática Digital (PMD) pode ser "concebida (ou definida) como narrativa multimodal digital utilizada para comunicar ideias matemáticas por meio de artes performáticas” (p. 108). Elas discutem as fases do processo de produção dos vídeos, apontando também algumas características e evidenciam o foco na perspectiva de despertar a atenção do espectador. Lembram ainda que o crescente acesso às tecnologias digitais e à internet facilitou tanto a produção quanto o compartilhamento dos materiais produzidos.

Numa análise conjunta destes trabalhos, e em conformidade com as afirmações das próprias organizadoras nas considerações finais, é possível constatar que não se percebem nos relatos apresentados na obra, instrumentos de coleta e análise de dados associados a uma metodologia de pesquisa. O foco está efetivamente atrelado à socialização de experiências desenvolvidas em sala de aula e que apontam vários contextos que permitem estabelecer conexões entre as abordagens da Matemática e da Arte.

Os autores transitam por diferentes espaços para sugerir elos entre estas duas disciplinas. Eles recorrem a elementos como moda, bordados, construções geométricas, pavimentações, origamis, fractais ou produções de vídeos, usando frequentemente as tecnologias digitais. Convém observar que a busca por estas relações contribui, em vários momentos, para trazer elementos que podem fazer parte do dia-a-dia dos alunos para as aulas 
Revista Triângulo

ISSN 2175-1609

\section{RESENHA / BOOK REVIEW / RESEÑA}

de matemática. De fato, no prefácio da obra o Prof. Dr. Marcelo de Carvalho Borba observa que "a relação entre matemática e arte é uma forma de aproximar o cotidiano escolar da vida fora da escola" (p. 12).

Ao estabelecer possibilidades de articulações entre o ensino de Matemática e a Arte, é possível constatar que os autores destacam a importância de proporcionar aos estudantes situações que favoreçam o desenvolvimento do potencial criativo e das aptidões. Eles insistem na premissa de que os alunos devem ter uma postura participativa e trabalhar com autonomia. Tal posicionamento permite ao leitor refletir sobre a possibilidade de abordar a matemática de forma diversa do que é feito no ensino tradicional, contribuindo para que os discentes tenham um papel mais ativo além de desenvolver percepções ampliadas desta ciência.

Todas as situações relatadas são acompanhadas de um plano de aula em que os autores esclarecem o público alvo, os conteúdos abordados, os objetivos propostos, além do tempo gasto e dos recursos necessários. São explicitadas também as etapas do desenvolvimento das atividades e descritos alguns dos resultados. Esta estratégia, ao expor passos a serem seguidos, imprime um caráter prescritivo ao texto. Acreditamos que o leitor interessado em utilizar as tarefas em sala de aula deve avaliar seriamente a possibilidade de fazer adequações, levando em consideração as especificidades do contexto em que atua.

Sugerimos que ainda há muito a ser discutido sobre as interfaces entre a Matemática e a Arte. O livro explora algumas situações que podem ser questionadas quando pensamos na sua exequibilidade na educação básica, além da omissão de propostas direcionadas aos anos iniciais, uma fase de escolarização que proporciona um vasto campo de aproximações entre estas áreas do conhecimento. No entanto, é conveniente frisar que a obra favorece o acesso a outros títulos e pode inspirar o leitor na elaboração de novas propostas, sempre levando em consideração as necessidades dos alunos e os objetivos que propõe alcançar. É importante dedicar especial atenção aos endereços eletrônicos que são disponibilizados ao longo dos capítulos, principalmente em notas de rodapé. Uma consulta a estes sites permite vislumbrar novos cenários para conectar a Matemática e a Arte. 
Revista Triângulo

ISSN 2175-1609

\section{RESENHA / BOOK REVIEW / RESEÑA}

Diante do exposto, é possível afirmar que a leitura deste livro, apresentado em uma linguagem clara e objetiva, pode ser proveitosa para professores da educação básica ou para pesquisadores que estão interessados em desenvolver estudos associados ao tema. Agentes educacionais que atuam no ensino superior com a formação docente também encontram na obra sugestões de atividades que podem ser desenvolvidas junto aos licenciandos.

\section{REFERÊNCIAS}

BORBA, M. C.; GADANIDIS, G; SCUCUGLIA, R. Fases das tecnologias digitais em Educação Matemática: Sala de aula e internet em movimento. Belo Horizonte: Autêntica, 2014. (Coleção Tendências em Educação Matemática)

TROJACK, C. L.; WROBEL, J. S.; OECHSLER, V. (Orgs.). Matemática com arte: sugestões de atividades interdisciplinares. Curitiba, Appris, 2017.

ZALESKI FILHO, D. Matemática e arte. Belo Horizonte: Autêntica, 2013. (Coleção Tendências em Educação Matemática) 